\title{
Cuatro altares de La Vera, Cáceres ${ }^{1}$ Four altars from La Vera, Cáceres
}

\author{
Joaquín L. Gómez-Pantoja \\ Universidad de Alcalá \\ José V. Madruga \\ Archivo Epigráfico de Hispania \\ Antonio González Cordero \\ Fundación Antonio Concha
}

\section{RESUMEN}

Se describen cuatro altares inscritos recientemente descubiertos en La Vera, comarca cacereña situada en la orilla septentrional del río Tiétar. De las nuevas inscripciones, tres son altares dedicados a lo que se han llamado "dioses indígenas": Band(-) Vortiacius, lo que parece una nueva paredria (Ulisus y Ulisona) y Quangeius; nótese que este se colocó in fano, la segunda mención epigráfica del término aparecida hasta ahora en la Península. La última pieza es un epitafio, pero tan estropeado por la erosión, que apenas se reconocen los elementos característicos de esta clase de epígrafes.

\section{SUMMARY}

This paper describes four Roman altars recently found in La Vera, which is the name given to the country lying between Tiétar river and Sierra de Gredos, in the Spanish province of Cáceres. Of the nine inscriptions, three epigraphs are dedications to local deities: Band(-) Vortiacius, a new divine couple, Ulisus and Ulisona; and Quangeius, this one being placed in fano, which is the second occurrence of that word in Spanish epigraphy. The last piece is a tombstone so dilapidated that it is difficult to tell apart even the normal features of an ancient epitaph.

${ }^{1}$ Una parte de este trabajo se ha realizado con fondos públicos del Plan nacional de investigación fundamental no orientada (proyecto de investigación HAR2011-29108-C04-02: El taller de ORDO: Representaciones gráficas de la influencia y el poder de las élites en la pars Occidentalis del Imperio Romano). Agradecemos las sugerencias y críticas de Carlos Búa (Heidelberg), José d'Encarnação (Coimbra), Amilcar Guerra (Lisboa), Blanca Prósper (Salamanca), Valentín Soria (Jarandilla de la Vera) y Ángel Jordán (Archivo Epigráfico de Hispania). Nuestra gratitud, también, a los propietarios de las inscripciones: Alfonso Abio Villarig, de la finca "Pascuala"; Francisco Alegre, de "El Salobral"; Luis Gómez, de la "Vega del Cincho"; y Ángel Sánchez, el tabernero con aficiones epigráficas. Sin su colaboración, no hubiera sido posible examinar ni fotografiar las piezas.
PALABRAS CLAVES: Epigrafía latina, Teónimos, Religión y culto, Hispania, Lusitania.

KEY WORDS: Roman Epigraphy, Theonyms, Religion and Cult, Roman Spain, Lusitania.

La Vera es el nombre que recibe la parte cacereña de la ribera norte del valle del Tiétar, un afluente por la derecha del río Tajo; se trata de una comarca natural, cuyos singulares rasgos derivan directamente de la morfología de la zona, de su clima y del modo en el que la actividad humana se ha adaptado a esas circunstancias ${ }^{2}$. En el fondo del valle, la abundancia de agua y la elevada insolación permiten que prosperen especies mediterráneas o semitropicales de gran valor comercial, que en los últimos cincuenta años se han convertido en cultivos extensivos gracias al regadío y el labrantío mecánico.

Desgraciadamente, la información sobre épocas pasadas es dolorosamente pobre y está desigualmen-

\footnotetext{
${ }^{2}$ Es corriente que "La Vera" y "Valle del Tiétar" se empleen como antónimos, sirviendo el segundo para designar la parte del mismo que está en la provincia de Ávila. Sin embargo, sus respectivos habitantes generalmente piensan que pertenecen a la misma comunidad geográfica. Lo interesante es que ese sentimiento tiene refrendo histórico, ya que el más reciente hallazgo epigráfico de la zona, un terminus augustalis del 5/6 d.C., atestigua que los limites de los avilenses se extendían por la vertiente meridional de la Sierra de Gredos hasta alcanzar el Tiétar a pocos Km al sur de Jarandilla de la Vera (GómezPantoja 2011; vid. Hispania Epigraphica Online (desde ahora HEpOl) 25098, en www.eda-bea.es (consultada 01/05/2012), como fácil referencia, para los datos del hallazgo, dimensiones de la pieza, fotos y completa bibliografía). Por este motivo, aquí emplearemos indistintamente los términos "La Vera" y "Valle del Tiétar", para referirnos a las tierras entre la ribera septentrional del curso medio del Tiétar y la Sierra de Gredos.
} 
te repartida en el tiempo, no remontándose las más antiguas series documentales más allá del siglo XIII. Para épocas más antiguas, los datos son aún más escasos y proceden fundamentalmente de prospecciones y hallazgos arqueológicos, la mayoría difíciles de datar y cuya significación histórica es muy variable; entre esas prospecciones caben destacar las que uno de nosotros viene realizando desde hace veinte años en $\mathrm{La}$ Vera cacereña, con interesantes resultados publicados (González Cordero y Hernández López 1992; Alvarado Gonzalo et alii 1993; Bueno Ramírez et alii 2000; Cerrillo Cuenca y González Cordero 2001; González Cordero 2003; 2005; 2007; vid. también Fernández Freire 2009).

El catálogo local de las inscripciones lo componen una treintena de piezas, de las cuales 18 proceden de La Vera cacereña y, el resto, de Candeleda y sus alrededores, en la parte avileña del valle. Es notable la abundancia de dedicatorias sagradas: 20 frente a 8 lápidas sepulcrales, 3 inciertas y un terminus augustalis. Se puede objetar que esa distribución está distorsionada por el hallazgo de 15 altares en el santuario de Velicus en Postoloboso (Fernández Gómez 1973; Hernando Sobrino 2005: cat. nn.142155; Schattner et alii 2006: 204), pero también cabe entenderlo como el reflejo de una comarca en la que el saltus —el dominio por excelencia de los diosesprevalecía sobre el ager, el paisaje humanizado; en consonancia con ello, los altares veratos están consagrados a las divinidades "indígenas", excepto una dedicación a Júpiter de Pasarón de la Vera (HEp 9, 1999, 253 = HEpO1 22608). Los restantes atestiguan el culto de Arabo Corobelicobo Talusico (dat.) en Arroyomolinos de la Vera (Esteban Ortega y Salas Martín 2003: cat. n. 18; HEp 13, 2003-2004: 215 = HEpOl 20343); a Toga y al deus Tritiaecius en Torremenga (Callejo Serrano 1963: 225 cat. n. 8 con foto $=$ HEpOl 20111, con foto; Blázquez Martínez 1979: 165 cat. n. 253 = HEpOl 25658); y a sendas divinidades indeterminadas, procedentes de Tejeda de Tiétar (HEp 3, 1993, 139 = HEpOl 22631) y de Torremenga (Hurtado de San Antonio 1977, cat n. 727). Tres de los cuatro nuevos epígrafes son precisamente altares, respectivamente consagrados a divinidades indígenas muy populares en Lusitania, Band(- - ) y Quangeius y a unos númenes no previamente atestiguados, Ulisus y Ulisona; la cuarta inscripción, muy estropeada, parece ser un epitafio.

\section{LOS EPÍGRAFES}

\subsection{Jarandilla de La Vera}

Ara de granito de grano fino y color ocre amarillento con vetas rojizas, cuyas dimensiones actuales son 87 x (32) x $25 \mathrm{~cm}$. El altar está mutilado, ya que se retocó la moldura de la basa, se igualaron con el neto los salientes por la derecha de la cornisa y basa y posiblemente se arrancó un filete del neto, provocando la perdida de una o dos letras al final de algunos renglones; hay también un golpe que arrancó una esquirla en la derecha del coronamiento: según nos informaron, algunos de esos

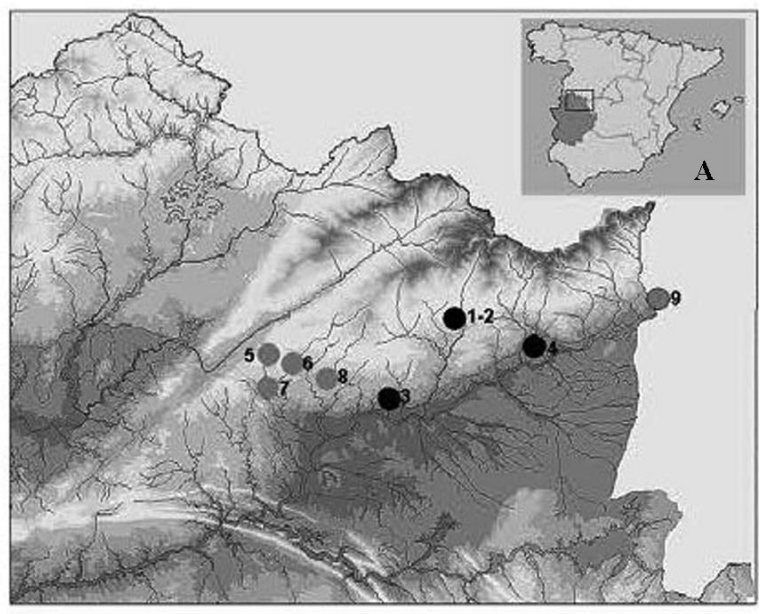

B

Figura 1. A: Situación de Extremadura en España; la zona recuadrada es la correspondiente a comarca de la Vera y que se amplía en B): Mapa de la Vera, mostrando los lugares de hallazgo de los epígrafes estudiados (1-2 Jarandilla; 3, Collado de la Vera; 4, Losar de la Vera) y de los aparecidos con anterioridad (5, Aroyomolinos de la Vera; 6, Pasarón de la Vera; 7, Tejeda de Tiétar; 8, Torremenga; 9 , Candeleda, en Ávila). (A. González Cordero). 
daños se produjeron durante la colocación de la pieza en la pared. En cambio, se conservaba bajo la basa un dado rectangular que debió servir para hincar el altar en tierra.

El campo epigráfico ocupa el neto, pero es muy probable que existiese una última línea en el frontal de la basa. Igualmente, el corte vertical del lado derecho sugiere la perdida de letras al final de las líneas 1-4. Las letras son capitales de muy buena factura, regulares y de surco profundo, que miden entre 6 (en lín. 2 , la T, $6,4 \mathrm{~cm}$ ) y $5 \mathrm{~cm}$ en el último renglón; nótense las $\mathrm{C}$ ultra-circulares.

Supimos de la existencia de la pieza por la nota que D. Valentín Soria remitió a uno de nosotros (JGP) el 21-03-2005, en la que comunicaba que, apenas una semana antes, había examinado, en la puerta de la "Taberna del Pregonero", un altar del que adjuntaba una imagen y las anotaciones hechas durante su examen, esto es, transcripción provisional y medidas aproximadas. A principios de diciembre de 2005, en compañía de A. Jordán, dos de nosotros examinamos el altar, que estaba embebido en la fachada del número 3 de la calle Las Espeñas, a la izquierda de la puerta del mencionado establecimiento. De acuerdo con lo que nos dijo su propietario, el epígrafe había llegado a sus manos a comienzo de ese mismo año, entregado por un amigo del vecino pueblo de Guijo de Santa Bárbara, con la condición inapelable de que lo colocase a la puerta del bar; también nos dijo que desconocía el lugar y la fecha en que se halló la inscripción, pero que le constaba que su anterior propietario la tenía "desde por lo menos 20 años" antes ${ }^{3}$. Con posterioridad a nuestra visita, el epígrafe fue removido de ese lugar, encontrándose actualmente en paradero desconocido, aunque no sería difícil volver a localizarlo haciendo algunas preguntas en el pueblo.

\footnotetext{
${ }^{3}$ Según hemos podido averiguar en Guijo de Santa Bárbara, no hay memoria de que se haya encontrado en el pueblo ninguna inscripción antigua y quienes respondieron a nuestras preguntas, buenos conocedores de la zona, están convencidos de que es improbable un hallazgo de esa clase, porque los restos más antiguos de poblamiento que se conocen son siempre posteriores a la época romana. No obstante, en una noticia leída en http://www.comarcadelavera.com/Jarandilla/Historia/ htm, consultado el 21/11/2001 pero que desapareció posteriormente, se afirmaba que "en el Cerro de la Berrocosa, apareció una inscripción partida que se encuentra en la actualidad en el Guijo (entiéndase, de Santa Bárbara). Sin más datos". La Berrocosa es un paraje situado al sureste de Jarandilla, dentro de su término municipal y en el lado norte de la carretera regional EX-119, y tradicionalmente se sostiene que de allí procede la estela figurada que recibe culto bajo la advocación de Virgen de la Berrocosa. No podemos asegurar que esta noticia se refiera al altar que publicamos, pero dejamos constancia de ella por si en el futuro se averigua algo más que aclare la procedencia del mismo.
}

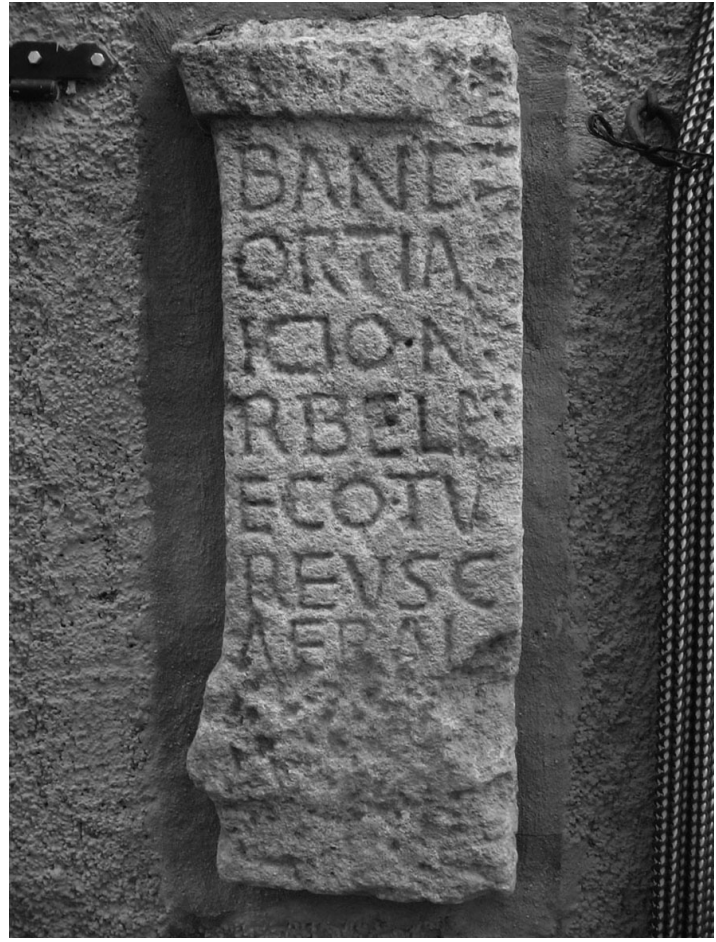

Figura 2. Dedicatoria a Band(-) Vortiacius, vista en Jarandilla de la Vera en 2005 (J. L. Gómez-Pantoja).

\author{
Band(i) [V]- \\ ortia- \\ icio $\cdot \mathrm{N}[]-$. \\ rbeln- \\ 5- eco $\cdot \mathrm{Tu}-$ \\ reus $\cdot \mathrm{C}$ - \\ aerai \\ [f(ilius) v(otum) s(olvit) l(ibens) m(erito)].
}

Lín. 1: BAND[E] Soria per litt. Es dudoso si lo perdido al final del renglón sea una o dos letras. En favor de esto último, puede aducirse que el teónimo raramente aparece abreviado en otros altares conocidos. Aquí sin embargo, se ha preferido restituir la inevitable inicial del epíteto, basándonos en que nada en el epígrafe indica una justificación del texto por la derecha ${ }^{4}$; y que la forma abreviada Band(-) está ya atestiguada en la llamada "pátera Calzadilla" (Blanco Freijeiro 1959 = HEpOl 20072, con foto), que es el

\footnotetext{
${ }^{4}$ Se puede aducir también la evitación del dígrafo -V V-. El fenómeno se da en un altar de Seixo de Ansiães, Carrazeda de Ansiães, Bragança: Bandu /Vorde/aeco, vid. FE 40, 1992: 179 (AE 1991: 1039; HEp 5, 1995: 986; HEpOl 7195), pero hay rotura de línea entre ambas letras y el hallazgo se produjo al norte del Duero, circunstancia con consecuencias lingüísticas, vid. infra.
} 
único testimonio abreviado seguro de estas características, porque el que pasa como tal para algunos (CIL II 855 = HEpOl 21823, de Malpartida de Plasencia), no puede sostenerse a la vista del apógrafo que Hübner tomó del antiquior; la solución $B$ (andi) V(orteaecio) s(acrum) para las siglas de la pieza de São Vicente da Beira, Castelo Branco, es meramente hipotética (Encarnação 1987: 20 = HEpOl 22960).

Lín. 2: ORTIA Soria, per litt. Al final del renglón hay sin duda espacio para otra letra, por lo que cabría leer $V /$ ortia[e]/icio; pero no la restituimos por dos motivos: el ya indicado de que no hay en el epígrafe indicio alguno de una norma compositiva que obligase a igualar los renglones por la derecha; y porque nuestra opción se ajusta perfectamente a la que se supone que fue la forma original del epíteto, *Vortiaikio (Pedrero 1999: 537).

Lín. 3 ext.: $\mathrm{A}[\mathrm{N}]$ Soria per litt. La letra mutilada debe de ser una $\mathrm{M}$ o una $\mathrm{N}$. La primera alternativa exige una letra tan ancha que apenas libraría espacio para la necesaria vocal siguiente, por lo que forzosamente esta debería ser I o A en nexo con la consonante. Y aunque Mirb- o Marb- no es menos plausible que N[.] $r b$-, preferimos esta última porque la identidad de la letra nos pareció indudable durante la autopsia de la piedra, apreciándose aún el bisel del fuste derecho sobre el borde de la rotura. Tras la N, una posibilidad es suplir [O], porque hay espacio para ello y la secuencia $\mathrm{No} / \mathrm{rb}$ - parece obvia dada la proximidad de Norba y el corriente uso de Norbanus como nombre personal.

Lín. 4 ext.: E Soria per litt. De la última letra solo se conserva el astil izquierdo y un poco del ángulo superior, por lo que en la autopsia quedamos que solo podía ser una $N$ o, improbablemente, una $\mathrm{M}$.

Lín. 7 ext.: L Soria per litt. De la R se ve el bucle, habiendo quedado obliterado el montante inclinado con el repicado de la parte inferior del altar, que también causó que de la A solo permanezca el vértice y la I haya pedido la parte baja del fuste.

Lín. 8: El patronímico exige probablemente la sigla de $f$ (ilius) y esta, más las correspondientes a la fórmula de dedicación, cumplen las 5 letras que lleva cada línea.

Actualmente, son más de 60 las menciones epigráficas de $B a n d{ }^{-5}$, lo que convierte a esta divinidad en una de

${ }^{5}$ El recuento es nuestro; el catálogo más completo publicado hasta ahora es el de Prósper 2002: 257-281, con 48 testimonios. La discrepancia se debe a los nuevos hallazgos, que no dejan de producirse, pero también a los criterios empleados en la compilación, pues no solo entra en juego la aceptación de muchas lecturas inseguras sino, sobre todo, la falta de unanimidad sobre qué se escondía bajo el teónimo Band-, porque al numen se le invocó de ese modo y, también, añadiéndole uno o dos epítetos que, a su vez, pudieron usarse como nombres sagrados. Conjugar adecuadamente tantas variables es una tarea que supera nuestra modesta aspiración, que no es otra que las mejor documentadas del panteón indígena de la Península. Paradójicamente, tal abundancia de testimonios no sirve para despejar las muchas incógnitas en torno a este numen, entre las que no son las menores la determinación de cuál fue su nombre y el género de este. La falta de acuerdo sobre la flexión del teónimo se debe a las múltiples desinencias que toma el único caso atestiguado hasta ahora, el dativo, lo que permite afirmar que todas las formas conocidas se reducen a un común Band-. La cuestión del género está ligada a la anterior; la idea más extendida es que, si los epítetos que lo acompañan son un indicio, se trata de un nombre masculino; pero hasta hace poco, la opinión mayoritaria era la contraria, en parte porque así lo aconsejaban las hipótesis etimológicas y en parte porque la única imagen que puede asociarse con el teónimo es, sin duda, femenina ${ }^{6}$.

Tampoco se sabe qué, quién o quiénes se ocultaba bajo la raíz Band-. Una plausible vía para averiguarlo es la determinación de la etimología, pero un repaso a las hipótesis planteadas desde fines del siglo XIX sugiere que el método es ineficaz, a la vista de la constante revisión del asunto (Prósper 2002: 269-272).

Las únicas certezas son las meramente empíricas. Primero, la distribución geográfica del culto se ciñe a las regiones más occidentales de Hispania, desde las costas septentrionales del Atlántico y el Cantábrico hasta la raya del Tajo, aunque se conoce algún caso que traspasa ese límite; y segundo, que en los epígrafes encontrados al norte del río Duero (es decir, en las regiones dependientes de la Hispania Citerior), $B$ and- forma el dativo con $-u e-u$, mientras que al sur del Duero (es decir, en la Lusitania), predominan las formas en $-i-e$ (Pedrero 1999: 537-538) y es por ello por lo que suponemos que, aunque abreviado, el teónimo de nuestro altar debía terminar en - $i$.

El apartado teonímico es robusto, ya que Band- va acompañado de dos epítetos. El primero, Vortiaicius, es también uno de los más frecuentes, pues está atestiguado en al menos otras cinco ocasiones y todas ellas, salvo una, proceden de la zona de dispersión meridional del teónimo ${ }^{7}$.

El segundo epíteto, en cambio, es inédito y ello dificulta acertar en la restitución de la letra perdida.

\footnotetext{
proporcionar solvencia a este artículo.

${ }^{6}$ Un resumen en Pedrero 1999: 536; pero la perplejidad continúa, vid. Bernardo Stempel 2003. Sobre el sexo gramatical de los dioses peninsulares, Encarnação 2002.

${ }^{7}$ HEp 17, 2008: 235 de Aldea de Santa Margarida, Idanhaa-Nova, Castelo Branco; HEp 13, 2003/2004: 990; AE 2003: 865 = HEpOl 25444, de Meda, Guarda; CIL II 855; AE 1999: 882; HEp 11, 2001: 122 = HEpOl 21823, de Malpartida de Plasencia, Cáceres y HEp 5, 1995: $994=H E p O l ~ 23171$, de Penamacor, Castelo Branco. El caso excéntrico es FE 40, 1992: 179 = HEpOl 7195, de Seixo de Ansiães, Carrazeda de Ansiães, Bragança.
} 
Como muchos de estos epítetos aluden a lugares, nótese su semejanza con Norba, que no en vano es el mejor conocido y más famoso topónimo de la zona. Pero ya hemos señalado que se trata de una reconstrucción hipotética y entra también en lo posible que sea el derivado de un antropónimo.

Finalmente, el dedicante. Tureus Caerai f. es, en gran medida, un estudio en lo vulgar ${ }^{8}$, porque el nombre del devoto está bien atestiguado tanto dentro de Lusitania como fuera de ella (Abascal Palazón 1994: 554- 555; Navarro-Ramírez 2003: 327, mapa 309 y Vallejo 2005: 441-442). Y aunque para el patronímico no hay paralelos estrictos ${ }^{9}$, ello carece de relevancia porque constan en abundancia formas como Caerus, Caerius y Caeria (Navarro-Ramírez 2003: 126 y Vallejo 2005: 242) y se conocen nombres similares con derivación en -aius, como sucede, — sin ir más lejoscon el propio nombre Tureus, para el que se documenta la forma Turai (gen.) (AE 1965: 75 = HEpOl 20112).

\subsection{Finca "Pascuala", Jarandilla de la Vera}

Altar de granito, conservado en su integridad salvo por la falta de la moldura lateral izquierda de la cornisa y un fuerte golpe que mató la esquina inferior izquierda de la basa; en la parte superior se mantiene el foculus, de planta romboidal y con las esquinas apuntando al centro de cada cara del monumento. Dimensiones actuales, 94 x 34 × $23 \mathrm{~cm}$. El texto votivo se divide en dos campos, con la primera línea en el listón superior de la cornisa y el resto, en el neto. Las letras son capitales de factura muy desigual y un tamaño medio de $5 \mathrm{~cm}$; la E (lín. 4 y 5) y la F (lín. 2 y 7), en forma de dos rayas paralelas; la G (lín. 1 y 5), con el espolón sinuoso; y la A (lín. 1-2, 4 y 7), con el filete anclado solo en el brazo izquierdo, inclinado e incompleto. También son significativas la forma en que dispuso la intepunción y la de ruptura de palabras entre líneas. Lamentamos la brevedad de la descripción, pero la autopsia se realizó en condiciones poco adecuadas e impuestas por las circunstancias.

El epígrafe procede de una zona situada al sur del término de Jarandilla de la Vera y en la orilla izquierda

\footnotetext{
${ }^{8}$ Puede incluso que esté atestiguado un individuo homónimo, ya que una fuente del siglo XVIII reporta la lectura Tureus Taerai f(ilius) en una lápida sepulcral aún visible en el lienzo oriental de la muralla de Coria (CIL II 788); desgraciadamente la pieza está ahora mutilada por debajo del primer renglón, pero a la vista del altar que editamos, cabe sospechar que el antropónimo Taeraius, sin otra ocurrencia que la señalada, no sea sino una mala lectura de Caeraius.

9 Ténganse en cuenta, sin embargo, el Caepai que figura en un ara de Jarilla (HEpOl 20803), otra localidad cacereña situada en el límite occidental del valle del Jerte.
}

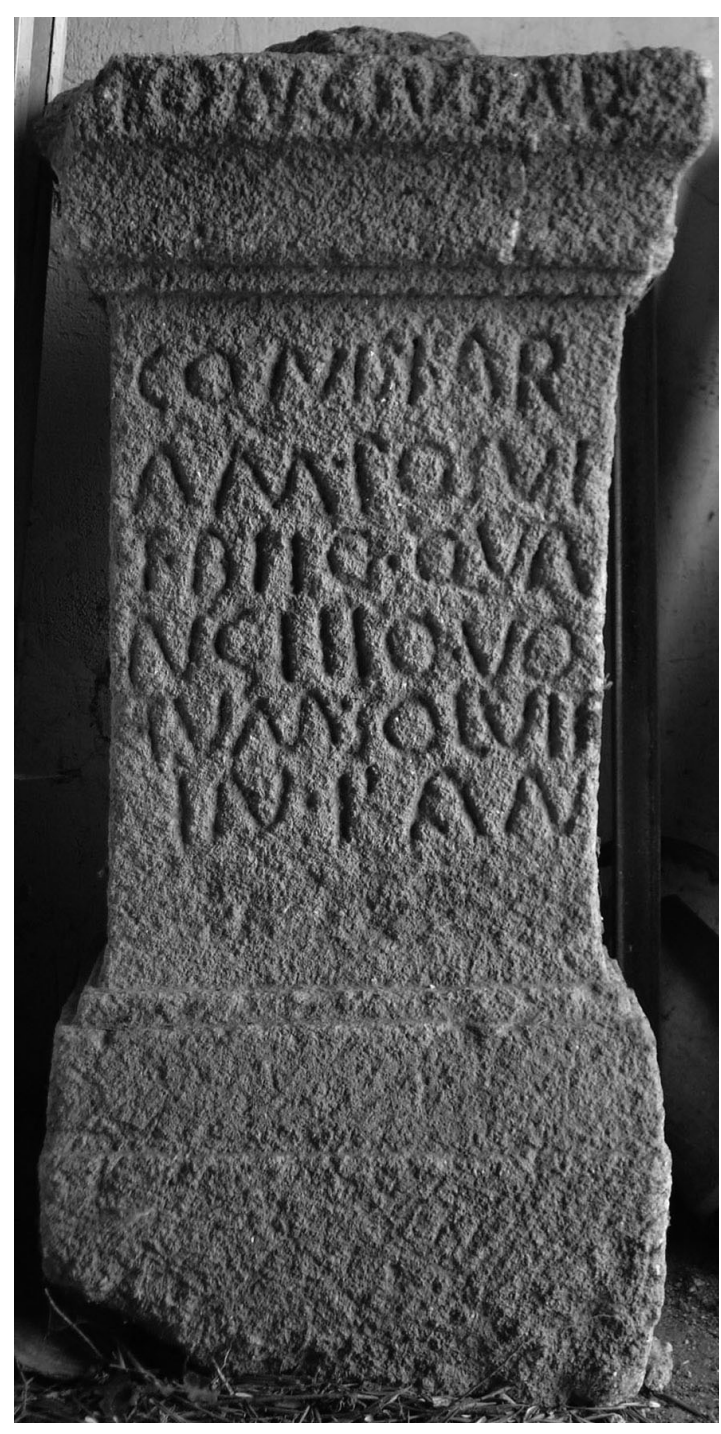

Figura 3. Altar de Quangeius, finca "Pascuala", Jarandilla de la Vera (A. González Cordero).

de la Garganta Jaranda, en la que se han detectado restos de al menos tres asentamientos antiguos, siendo el más importante aquél en cuyas cercanías se identificó la base de un mausoleo romano (González Cordero y Hernández López 1992). La inscripción se encontró un poco más al sur de ese punto, en dirección a la Dehesa Chica y a la finca "Pascuala", donde se constata también la existencia de distintos restos constructivos antiguos, sillares almohadillados o con molduras, un contrapeso de prensa olearia, cerámicas comunes, algunos fragmentos de terra sigillata, escorias, vidrios, restos de un horno y partes de la cimentación de una casa; más significativo es que en esa misma área se halló otro epígrafe latino, re-aprovechado como jamba 
en la puerta de una caseta agrícola ${ }^{10}$. Al igual que sucede con el altar siguiente de "El Salobral", en la zona hay una surgencia salada — la llamada "Fuente de la Sal"- - que goza de gran reputación en la zona. La inscripción se encuentra depositada en una dependencia de labor de la finca "Pascuala".

$\begin{array}{ll} & \text { Tongius } \cdot \text { Ar- } \\ & \text { conis } \cdot \mathrm{f}(\text { ilius }) \text { ar- } \\ & \text { am } \cdot \text { posui- } \\ \mathrm{t} \cdot \text { deo } \cdot \text { Qua- } \\ \text { 5- } & \text { ngeio } \cdot \text { vo- } \\ & \text { tum } \cdot \text { solvit } \\ \text { in } \cdot \operatorname{fan}(\mathrm{o}) .\end{array}$

En la última línea sorprende que se haya abreviado fanum, puesto que hay espacio para haber acomodado el final de la palabra; sin embargo, antes que conjeturar que se debe a la ineptitud de un cantero, debe notarse que hay suficientes ejemplos del uso de la abreviación fan (um) en epígrafes en que se mencionan santuarios concretos $^{11}$.

Arco y Tongius son nombres tan corrientes en la Península y, especialmente, en Lusitania (NavarroRamírez 2003: 98-99, mapa 37 y 322-323, mapa 301; Vallejo 2005: 178-180 y 419-423) que no merecen mayor comentario. Quangeius, por su parte, es un numen del que hay otros testimonios, todos procedentes de la Lusitania, salvo uno encontrado en una zona limítrofe de la Citerior (Garcia 1985), siendo el de Jarandilla de la Vera el más oriental de la decena de altares conocidos ${ }^{12}$. Desgraciadamente, fuera de

${ }^{10}$ Soria Sánchez 1979: 909-910, con la corrección de Curchin 1985 (AE 1985: 546; HEp 1, 1989: 167 = HEpOl 22597). La mayor parte de de las piedras que se hallaban dispersas por la zona fueron empleadas para levantar el puente de la Garganta de Jaranda y la iglesia de Santa María de la Torre, en Jarandilla de la Vera; en el aparejo de los muros de esta última son visibles un pulvino, un verraco y, al menos, otras dos lápidas, localizadas recientemente por uno de nosotros. La primera se halla en el interior de la enjuta de uno de los arcos que fajan la nave; desde ésta se distingue bien la cabecera redondeada del monumento, pero no se aprecia texto, quizá por la altura a la que se halla, porque se ha borrado el letrero o porque éste se encuentra dispuesto hacia el interior del muro. La segunda inscripción sirve de alféizar de una de las ventanas que da a la plaza del pueblo y debido a que se colocó con el epígrafe hacia abajo, sólo son legibles las primeras letras de cada una las once líneas que lo forman.

${ }^{11}$ CIL IX 3523, de Barisciano/Furfo: cur(atores) fan(i); CIL X 3924, de Capua: mag(ister) fan(i) Dian(ae) Tif(atinae); y CIL XIV 4258, de Tivoli/Tibur: cur(ator) fan(i) H(erculis) V(ictoris).

${ }^{12}$ Malpartida de Plasencia: Hurtado de San Antonio 1977: cat. n. 743, con la corrección de Encarnação 1987: 29 (HEp 3, 1993: 127 = HEpOl 22621), donde la divinidad es invocada como D(eus) Quangeius. De Penamacor, Castelo Branco, proceden dos altares: uno del propio Penamacor: Curado 1984, enmendado en $F E$ 10, 1984: p. 9: Add. et corr. (AE 1984, ese reparto geográfico y de la especulación sobre los epítetos que acompañan al teónimo en uno de los altares de Nisa (Quangeius Tanngus) y en el de Alfenim (Quangeius Turicaecus), poco más se puede decir de los atributos y cualidades de la divinidad y de las aspiraciones de sus devotos.

En cambio, lo que si merece comentario es el apartado teonímico y la fórmula votiva, que aquí aparecen seguidas: aram posuit deo Quangeio, votum solvit in fan $(o)$. Por una parte, se menciona un fanum que es una de la posibles designaciones latinas de un santuario; su campo semántico primigenio parece referir a un área o espacio consagrado ${ }^{13}$, pero el término evolucionó hasta incluir en su significado las estructuras y construcciones existentes en esos loca sacra; a pesar de tan amplia y ambigua significación (Dubourdieu y Scheid 2000: 72 y ss.; González Rodríguez 2008), se ha notado que apenas se usa en las inscripciones de la Urbe, pero que en cambio sí que están atestiguados diversos fana y, ocasionalmente, los magistrados o curatores encargados de ellos, en distintos lugares de Italia y de otras provincias ${ }^{14}$. En Hispania, por el contrario, faltan referencias a los fana en las fuentes literarias y el nuevo altar contiene la segunda mención epigráfica de un fanum en Hispania, tras el reciente hallazgo de una inscripción similar en Trujillo (Carbonell i Manils y Gimeno Pascual 2005, con los comentarios de AE 2005: 766 y HEp 14, 2005: 99), un lugar no muy alejado de Jarandilla de la Vera.

$478=$ HEpOl 20483); y otro de la freguesia de Bemposta: $A E$ 1982: 476, corregido por Garcia 1991: cat. n. 181 (HEp 4, 1994: 1044 = HEpOl 24160). Capinha, Fundão, también en Castelo Branco: $A E$ 1977: 356 = Garcia 1991: cat. n. 592 = HEpOl 20290. En Sortelha, Sabugal, Guarda, también se encontraron una pareja de aras: Curado 1987b $(A E 1988,695$; HEp 2, 1990: 805 = HEpOl 20564. Y AE 1988: 696; HEp 2, 1990: $805=$ HEpOl 20565). Otras dos más en Nisa, Portalegre, una en la propia Nisa: Curado 1987a (HEp. 2, 1989: 830) y la otra en la freguesia de Montalvão, Nisa: Encarnação 1984: cat. n. 641 (HEp 1, 1989, $687=$ HEpOl 23580). En Borba, Evora: Alfenim 1991 (HEp 4, 1994: 1056; AE 1991: 946 = HEpOl 20616). Por último, el único testimonio encontrado hasta ahora fuera de Lusitania procede Vilar de Servoi, Castrelo do Val, Ourense: Rodríguez Colmenero 1997: cat. n. 91 = HEpOl 7651 .

${ }^{13}$ Vid., por ejemplo, Liv. 10.37.15; Suet. Div. Iul. 54.2, aún distingue fana templaque entre las destrucciones causadas por César durante sus campañas galas. Cfr. Woodard 2006: 150.

${ }^{14}$ Italia: fana Dianae, Feroniae, Fortunae, Fugitivi, Voltumnae, etc, a partir de los datos de Smith 1857 y Stilwell et alii 1976, s.v. Fanum Fortunae es la actual Fano, en Umbria. Sobre la toponimia francesa derivada de fanum, vid. Nègre 1990: 162; además, desde comienzos del siglo XX, los arqueólogos franceses y alemanes designan como fanum a un edificio porticado, de planta cuadrada, rectangular o circular, que identifican como lugar de culto; estas estructuras son tan numerosas que se cuentan más de 650 fana (o "fanums") solo en Francia, vid. Fauduet et alii 1993. 
Por otro lado, y tomada en su literalidad, la fórmula votiva implica un grado de distancia temporal y/o espacial entre la colocación el altar y el cumplimiento del voto, lo que parece contradecir el testimonio de otros miles de aras, cuya bien conocida fórmula señala que el depósito de esta constituía la voti solutio; y, en todo caso, si se trataba de actos distintos y consecutivos, el orden lógico hubiera sido la resolución del voto primero, seguida de la conmemoración inscrita del mismo. Sin embargo, existen algunos epígrafes que inclinan a pensar que la expresión de nuestro de altar no es superflua ni redundante, sino que se trata de un pleonasmo mediante el cual el devoto intensificó el valor de su acción frente a la divinidad. Así, en un ara de Caleruela, Toledo, la secuencia que nos interesa se repite casi al pie de la letra y también en Trujillo ${ }^{15}$. No son estos los únicos casos, porque se encuentran paralelos menos estrictos en varios lugares de Hispania y de otras provincias ${ }^{16}$.

\subsection{El Salobral, Collado de la Vera}

Ara de granito de grano fino y color amarillento pardusco, cuyas dimensiones actuales son $75 \mathrm{x}$ (37) $\mathrm{x}$ (12) $\mathrm{cm}$. Conserva íntegramente la estructura de cornisa, fuste y basa pero, salvo en la cara inscrita, los otros lados presentan un visible desgaste, especialmente en el coronamiento, que ha perdido completamente el foculus. Se trata de abrasiones intencionadas, comparables a las concavidades que presentan los molinos de mano, lo que apunta al uso de la piedra como afiladera.

El frontal se conserva mucho mejor que las otras caras, seguramente porque el altar estuvo volcado sobre él, lo que también explica el severo desgaste de sus aristas. Con todo, la inscripción presenta varios arañazos y roces que afectan notablemente la lectura de las lín. 4-5 y han obliterado casi completamente la O en lín. 7. Las letras miden $4 \mathrm{~cm}$ y debe señalarse la selectiva convivencia de la grafía habitual de la $\mathrm{E}$

\footnotetext{
${ }^{15}$ Caleruela: Bassus Turobri(gensis), eques alae Vettonum, aram posit Ataecinae, votum solvi(t) [l]iben[s] [merito] en González-Conde Puente 1988, enmendando la editio princeps (AE 1986: 426; HEp 1, 1989: 602); todos los datos sobre este epígrafe, incluyendo descripción y bibliografía, en $\mathrm{HEpOl}$ 166. Trujillo: [- - Alb?]urus Tancini l(ibertus) Nabi<e $>$ s(acrum) a(nimo) l(ibens) aram posuit et vot(um) sol(vit) (HEpOl 25570).

${ }^{16}$ HEp 17, 2008: 1, de Ávila, Lusitania; HEpOl 25920 (con foto), de São Vicente da Beira, Castelo Branco, Lusitania; HEpOl 6779, de Giela, Arcos de Valdevez, Viana do Castelo, Hisp. Citerior; Morestin 1976: cat. 1 con fig. 1 (AE 1976, 33); Espinosa 1986: cat. n. 59 con lám. 9 (HEpOl 14647), de Rasillo de Cameros, La Rioja, Hisp. Citerior; CIL III 7535, de Constanta / Tomi, Moesia Inf.; CIL VII 276, de Greta Bridge, Britannia; CIL VIII 16759, de Fedj Meraou, Africa Procos.
}

con la arcaica o cursiva, es decir, la formada con dos rayas verticales: la primera aparece en las palabras “corrientes", como la conjunción de la lín. 1 o el nombre del dedicante, mientras que la segunda se restringe a los nombres sagrados. También es notable la A de la lín. 5, con características similares a las ya señaladas en el altar anterior; por último, entre la M y la O de la lín. 7 hay un claro trazo intermedio que no supera la mitad de la caja y que puede ser un rasgo accidental o que quizá protegía la cola de la Q de la lín. 6.

Según se nos informó, el hallazgo se produjo en la ribera septentrional del Tiétar, conocida como "Vega de Jaraíz", en el curso de unos trabajos de explanación agrícola junto a uno de los pozos de agua mineralizada que dan a los alrededores el nombre de "El Salobral". Aunque el sitio pertenece al ayuntamiento de Collado, está inmediato al río y a la muga de Jaraíz y, de hecho, desde hace varios siglos, "El Salobral" no se entiende tanto como una referencia a las surgencias mencionadas, cuanto a la advocación de la Virgen de ese nombre, que es precisamente la patrona de Jaraíz de la Vera; al trasladarse el culto a esa localidad, la ermita que lo alojaba cayó progresivamente en ruina y hoy día el solar lo ocupa una nave agrícola, aunque

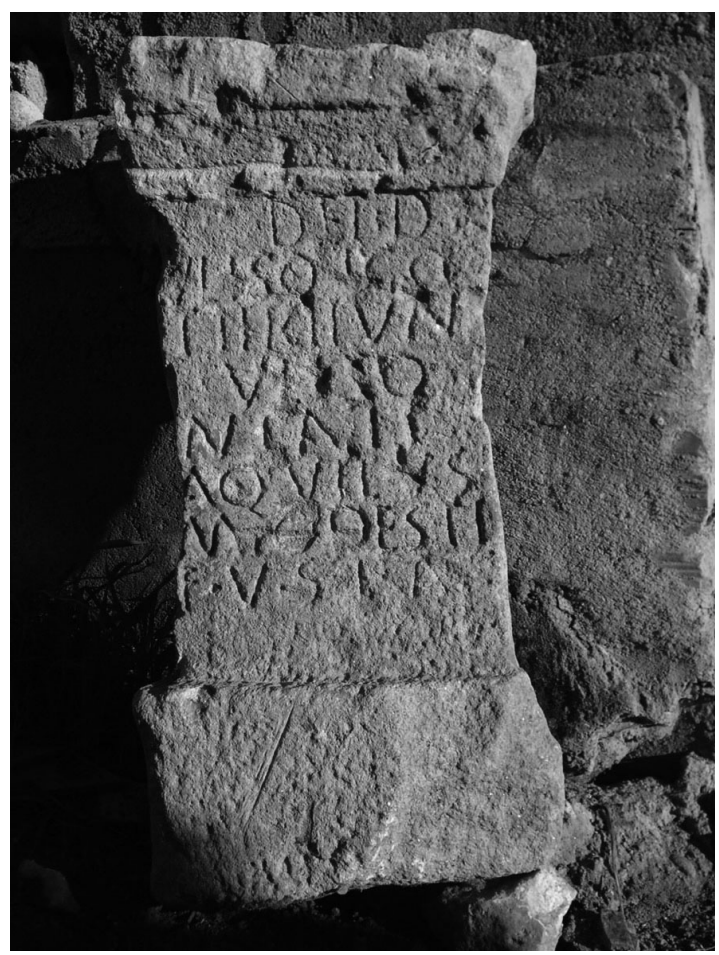

Figura 4. Ara de una pareja divina, finca "El Salobral", Collado de la Vera (A. González Cordero). 
todavía está viva la memoria de la fachada del edificio original, adornada con un par de escudos eclesiásticos. Más interesante a nuestros efectos es que, por toda la "Vega de Jaraíz", los tractores y máquinas subsoladoras empleadas en los cultivos intensivos, ponen al descubierto cada año los restos característicos de asentamientos agrícolas romanos — molinos, tegulae, sillares y restos de opus caementicium - que se acarrean hacia las orillas del Tiétar, donde sirven para la salvaguarda y contención de las fuertes crecidas del río (González Cordero 2007).

El altar lo conserva su descubridor en un lugar colindante con la finca "El Salobral".

\author{
$\mathrm{D}(\mathrm{eo})$ et $\cdot \mathrm{d}($ eae $)$ \\ Uliso Igo- \\ tereun $(0)$ \\ Uliso- \\ 5- niae \\ Aquilus \\ Modesti \\ f(ilius) v(otum) s(olvit) l(ibens) a(nimo).
}

\section{Lín. 2: VLISOIGO lapis - 3: TIIRIIVN - 4: VLIṢO - 5: NIAII}

La transcripción del epígrafe no presenta más dificultad que la derivada del mal estado de las letras del cuarto renglón que, sin embargo, puede leerse con cierta seguridad porque el mismo nombre se repite en el segundo. Tampoco la interpretación del texto es difícil, pues se identifican inmediatamente los tres elementos de las dedicaciones votivas: nombre divino, dedicante y ofrenda. Otro asunto distinto es la interpretación del apartado teonímico que, ocupando las cinco primeras líneas de la inscripción, es el rasgo más notable del monumento y, sin duda, el más significativo.

La primera parte de la advocación divina está clara: comienza en la lín. 1 con unas siglas que sustituyen la fórmula deo et deae, deabus et dibus y sintagmas similares que figuran en muchos exvotos lusitanos y de otros lugares de Hispania; expresiones compactas como la de nuestro altar, en cambio, resultan excepcionales y solo hemos sido capaces de encontrar otros dos ejemplos, bien distantes entre sí ${ }^{17}$. Fórmulas como Dis deabusque y similares implican la mención colectiva a númenes de ambos sexos que no precisan individualización, salvo que se trate de divinidades plurales como los Campestres, Consentes, Fatales, Hospitales,

${ }^{17}$ CIL III, 8186; Dragojevi -Josifovska 1982: cat. n. 3, de las proximidades de Skopje/Scupi, Macedonia, y Callejo Serrano 1967: cat. n. 16; HEpOl 6399, con foto, de Plasenzuela, Cáceres, un lugar situado a unos $90 \mathrm{~km}$ al sur de la Vega del Tiétar.
Momentis o Penates ${ }^{18}$; o específicas de algún lugar, al estilo de los dis deabusque Call(- -), Caulecisaecis, Coniumbrigensium, Urbisalviensibus, etc ${ }^{19}$.

Parece lógico suponer que el altar de "El Salobral" se ajusta a la misma práctica y que la larga secuencia, que ocupa las líneas 2-5, se refiere a un colectivo divino calificado con epítetos tópicos. Pero la dificultad reside en determinar cuáles fueron esos dioses, ya que faltan indicios claros para la correcta segmentación de la secuencia teonímica: no se aprecia interpunción; tampoco ayuda la división de palabras entre líneas y, para terminar, en la larga invocación no se distingue ningún nombre divino previamente conocido. Un epígrafe votivo, recientemente descubierto en Viseu, presenta un apartado teonímico cuya estructura no solo es similar al que nos ocupa, sino que comparte con él una secuencia sobre la que apoyar una posible segmentación: Deibabor igo deibobor Vissaieigobor, que ha sido entendido como la expresión en un dialecto céltico de una fórmula clásica: Deabus diisque Vissaieicis, esto es, las diosas y dioses propios del lugar que actualmente conocemos como Viseu (Fernandes et alii 2009: 146; cf. AE 2008: 643 y HEp 17, 2008: 255). Sin embargo, no parece que el paralelo sea válido porque habría que explicar por qué en nuestro altar se usó la conjunción et y no IGO; además-como veremos a continuación-, el resto de los nombres se flexionan usando las desinencias latinas: es decir, a diferencia de la inscripción de Viseu, la nuestra está escrita en latín ${ }^{20}$.

Debe partirse, pues, del análisis morfológico de la propia fórmula teonímica y continuar a partir de los resultados de este, en la medida en que se pueda. El primer rasgo llamativo es la repetición, en las lín. 2 y 4, de la secuencia VLISO, cuyo identidad viene asegurada porque el comienzo de la primera ocurrencia

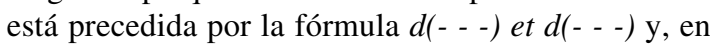
el segundo caso, por la singular disposición gráfica de la lín. 4. Además, en ambos casos, el radical parece acompañado de sufijos distintos, lo que sugiere una inicial segmentación tripartita del teónimo: VLISOIGO / TIIRIIVN, VLISO/NIAII. La última línea debe de

${ }^{18}$ Dii deaeque Campestres: Szabó y Tóth 2003: cat. n. 27, Bölcske, Hungría; Consentes: Schallmayer 1990: cat. n. 743, de Bone/Hippo Regius; Momentis: AE 1946: 69, de Timgad/ Thamugadi; Hospitales Penatesque: Collingwood y Wright 1965: cat. n. 649, de York/Eburacum.

${ }^{19}$ Deabus et dibus Call(- - -): HEpOl 23040, Valdeobispo, Cáceres; Caulicisaeci: HEpOl 8044, de Villalís de la Valduerna, León; Coniumbrigenses: HEpOl 21449, de Numão, Vila Nova da Foz Coa, Guarda; Urbisalvienses: CIL IX 5529, de Urbisaglia / Urbs Salvia, Italia.

${ }^{20} \mathrm{Sin}$ embargo, el apartado teonímico difiere del resto del texto por preferir sistemáticamente letras con formas arcaizantes; cabe conjeturar sobre las razones del fenómeno, pero es posiblemente arriesgado atribuirle valor semántico. 
ser un sufijo porque la lectura es segura y, en esas circunstancias, falta cuerpo suficiente para considerarla una palabra completa; además, VLISONIAII aparenta ser un femenino, lo que se conforma adecuadamente con la invocación inicial. Distinto es lo que sucede con VLISOIGO porque, por un lado, -igo/-ico es un sufijo muy corriente en la teonímia peninsular pero la terminación -oigo parece inusual. Por ello, a salvo de mejor opinión y mientras nuevos testimonios resuelvan la duda, nos inclinamos provisionalmente por esta otra segmentación: VLISO, IGO/TIIRIIVN ${ }^{21}$, VLISO/NIAII, que sigue siendo tan conveniente como la anterior desde el punto de vista de la sintaxis y el significado del epígrafe.

Como IGOTIIRIIVN no puede ser una forma completa latina, hay dos posibilidades que contemplar; la primera es que se trate de uno de los característicos genitivo plural en -un de las lenguas peninsulares, al estilo de Celtigun (CIL II 6298; HEpOl 12615), pero este tipo de formas solo se documentan en nombres personales. La segunda posibilidad es pensar que lo que se escribió fue IGOTIIRIIVN[I], habiéndose borrado la desinencia final (de dativo, como corresponde) con el deterioro del monumento; la autopsia de la piedra no autoriza esta hipótesis, incluso a pesar de la herida/rasgo que se ve en la foto tras la $-n$; pero se llega al mismo resultado considerando que lo que tenemos es una forma abreviada: Igotereun(o, - $i$ o similar).

Estas consideraciones llevan a la hipótesis de dos teónimos, uno femenino y otro similar, pero masculino y con epiteto: Ulisonia y Ulisus Igotereun(us, -is). La existencia de parejas divinas es considerada una característica de la religiosidad céltica y en la propia Lusitania se da el caso canónico de Arentius/ Arentia, cuyos devotos los adoraron simultáneamente de forma conjunta e individual y empleando solo sus respectivos teónimos o esos con epítetos (Olivares Pedreño 1999), que no agotan las ocurrencias de paredrías en esa y otras provincias. Están también Cosus (Olivares Pedreño 1997: 213) y Cosunea que, según algunos, figura en una dificultosa inscripción rupestre de Lamoso, Paços de Ferreira, Porto (HEpOl 11944 y 11945); Mandiceus y Mandica (respectivamente AE 1959: 203 = HEpOl 20066 y CIL II 5669, ambas de Astorga, León); Trebaronis/Triborunnis (AE 1958: 17 = HEpOl 16758 y AE 1985: $514=$ HEpOl 18502); Trebaruna/Trebaronna (HEp 5, 1995: $256=\mathrm{HEpOl}$ 16448; AE 1896: 2 = HEpOl 19979; AE 1934: $20=$

\footnotetext{
${ }^{21}$ Nótese que la mayor separación entre VLISO e IGO puede tenerse como indicio de dos palabras distintas; pero la comparación con lo que sucede con Modestus en lín. 7, obliga a aceptar que el desigual espaciamiento de los caracteres no es significativo.
}

HEpOl 20029; HEp 12, 2002, 93 = HEpOl 20182; AE 1977: 381 = HEpOl 20305; HEp 13, 2003/2004: 992 = HEpOl 23173); Borvo/Bormo/Bormanus/Bormanicus y Damona (Troisgros 1975) y Boruoboendoa (Vollgraff 1931: 256-257 cat. n. 5, de Utretcht, pero vid. ahora Delamarre 2004).

El caso de Igotereun( us, -is) es inédito en Hispania, aunque su primer elemento aparece ocasionalmente en la onomástica mediterránea ${ }^{22}$ y recuerda a la forma Ico- que consta en algunos nombres divinos, personales y de lugar de la Céltica propia ${ }^{23}$. Hay, sin embargo, una dificultad sintáctica con esta propuesta y es que mientras los teónimos se expresan en asíndesis, las siglas de la invocación inicial van unidas con la preceptiva copulativa y obligatoriamente deben desarrollarse como formas singulares, lo que lleva a la incongruente situación de que deus, dea no preceden a los respectivos teónimos. La situación es irregular y no tiene explicación, salvo que se entienda que quien escribió/grabó el epígrafe se atuvo a la fórmula habitual sin preocuparse de las menudencias sintácticas.

\subsection{Altar funerario de Losar de la Vera}

Fragmento de un altar de granito del que solo se conserva el coronamiento y parte del neto, habiéndose perdido el resto de este y la basa; sus dimensiones actuales son (89) x 40 x 40. Hasta su descubrimiento, la pieza estuvo parcialmente enterrada boca abajo y ello justifica el distinto grado de desgaste del letrero, que aparece estragado en los renglones expuestos a los agentes atmosféricos y en relativo buen estado en la parte que permaneció bajo tierra. El campo epigráfico mide $(73,5)$ x 40 y las letras, 5,6, aunque su factura es muy descuidada. El hallazgo se produjo cerca del Puente del Cincho, sobre la Garganta de Cuartos, donde hay un amplio campo de ruinas, muy arrasadas, en el que aflora abundante material latericio romano y cascos cerámicos. La pieza la conserva su propietario en un cuarto de labor de la finca "Vega del Cincho", en Losar de la Vera.

\footnotetext{
${ }^{22}$ Igocatus: $A E$ 1964:143a, de Aleria en Córcega e Igodia: Vives 1969: cat. n. 591, de cronología tardía pero incierta procedencia. Otro aparente paralelo peninsular se encuentra en Iccona Loiminna, la desconocida divinidad mencionada en la dedicación rupestre del Cabeço das Fráguas, vid. Tovar 1966-1967 (HEpOl 23173); pero la etimología del primer elemento del teónimo va contra esa posibilidad, vid. Prósper 2002: 51-52.

${ }^{23}$ Dea Icovellauna: CIL XIII 3644, de Trier / Treveris y 4296-8, Metz / Divodorum; Icotasgus: AE 1994: 1123i, de Leicester / Ratae Coritanorum y CIL XIII 2902, de Entrainssur-Nohain / Intaranum; Icorandus: CIL VI 3265; Speidel 1994: cat. n. 569.
} 


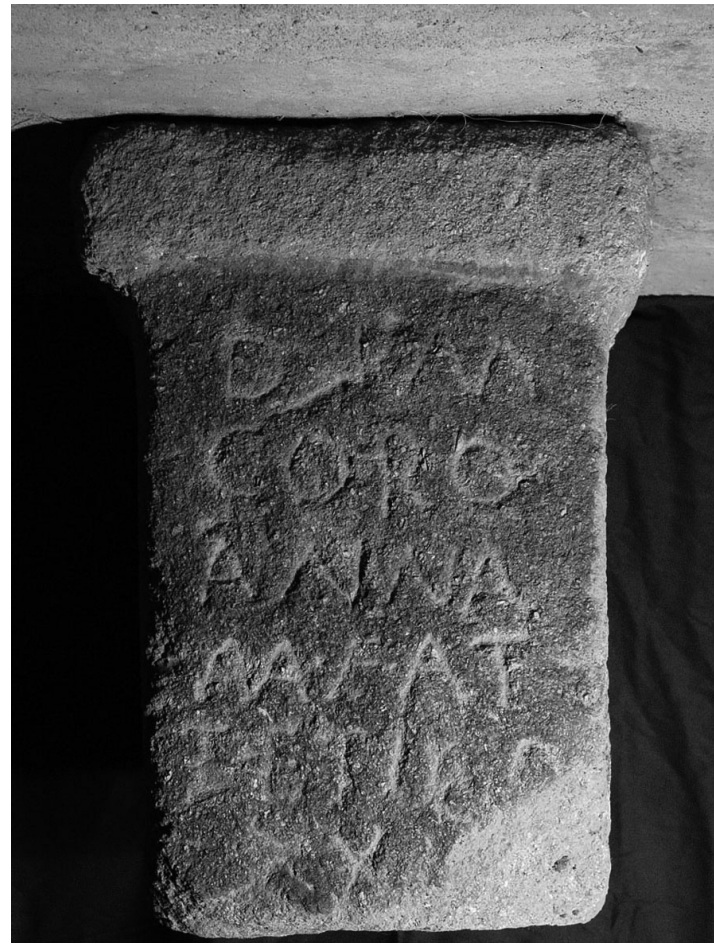

Figura 5. Altar funerario de Losar de la Vera (A. González Cordero).

D(is) i(nferis) m(anibus)
Coro
Anna
M A $\cdot$ F $\cdot$ AT
TE + ICO
$[---]+\mathrm{X}[---]$
$\left[----_{-}\right]$

Lín. 4: Se ve claro el nexo MA, seguido de lo que parece una $\mathrm{F}$ con el astil inclinado a la derecha, posiblemente una forma cursiva.

Lín. 5: La cruz corresponde a un rasgo vertical, con otro perpendicular arriba, pero del que solo se aprecia el lado derecho. Puede ser una T, pero las otras dos llevan un montante claro.

Lín. 6: A primera vista, un numeral, pero solo el segundo signo es claro y seguro.

Se trata de un ara con coronamiento simple, que es un soporte usado en la provincia de Cáceres únicamente para dedicatorias sacras (HEpOl 22633 de Valverde del Fresno y 22850 de Zorita). Sin embargo, las siglas ${ }^{24}$ del primer renglón dejan claro que no puede

\footnotetext{
${ }^{24}$ Se trata de una variante de la común invocación a los Manes, escasamente empleada en las provincias hispanas (Velaza 1995) y cuyos hallazgos dibujan un reparto geográfico poco significativo, vid. HEpOl 1791, 6265, 7313, 8291, 8451, 8547
}

tratarse más que de un epitafio, en el que Anna parece la dedicante (y quizá, la mater), mientras que Corus - un cognomen suficientemente atestiguado en Roma y otros lugares, aunque no en Hispania ${ }^{25}$-, puede ser el difunto y quizá también, el hijo, a tenor de la $\mathrm{F}$ de la lín. 4; como alternativa, se nos ha sugerido leer Coroanna, dado que existen en la Península Ibérica algunos nombres personales y divinos prefijados con Coro $^{-26}$. Nos parece que esa posibilidad complica innecesariamente la sencilla estructura del epitafio, pero lo cierto es que a partir de la lín. 2 impera la incertidumbre, porque en el renglón siguiente puede ir un nombre como Atte[t]ico o, por el contrario, dos nombres abreviados, Att(- - -) et Ico(- - -), seguidos de un numeral, que debe de corresponder a la edad, aunque no está claro dónde puede estar la indicación annorum. En definitiva, una inscripción en la que solo se reconocen algunos de los elementos habituales de un formulario fúnebre, ya que el texto nos ha llegado muy corrupto.

\section{DATACIÓN Y CONCLUSIONES}

Fechar inscripciones es más un arte que una ciencia, porque pocas piezas proporcionan una data explícita; para el resto, se recurre a indicios de relativo valor y cuya eficacia está marrada por diversas consideraciones. De ahí que se rehúyan las opiniones cronológicas y que, cuando se dan, esas fechas admitan 50-100 años de latitud. Por otra parte, opiniones e hipótesis fundadas en conjuntos epigráficos extensos son, por lo general, mucho más fiables que las obtenidas de unas pocas piezas; y los epitafios, con sus variados manierismos, resultan más fructíferos a estos efectos que las escuetas dedicatorias sacras. En consecuencia, datar cuatro epígrafes procedentes de una aislada zona rural (o, incluso, peor, silvícola) y de los cuales, además, tres son exvotos, es seguramente el

8708, 14020, 15666, 16061, 16248, 16353, 19245, 22095, 24138 , y 25038.

${ }^{25}$ Vid. CIL VI 4469, 16103, 20305, 22357, de Roma; VIII 18065, de Lambaesis, Numidia; AE 1897: 117c, de Mainz / Mogontiacum, Germania Sup.; curiosamente, el nombre no aparece listado en Lórincz 1994, s.v. que, en cambio, sí recoge las variantes Corro y Corrus.

${ }^{26}$ Antropónimos: Corocaudus: CIL II $2462+$ HEp 17, 2008. 744 (HEpOl 21853), de São Paio de Meixedo, Viana do Castelo; Corovescum: CIL II 5730, de Cangas de Onís / Vadinienses; Corogenus: Redentor 2002: cat. n. 85, de Donai, Bragança; Corobultus: FE 7, 1984: 29 + HEp 13, 2003/2004, 993 (HEpOl 20487), Santo Estêvão, Sabugal, Guarda; Coropotus: HEp 13, 2003-2004: 140, de Torrejón el Rubio, Cáceres; Coropolia: Rodríguez Colmenero 1997: cat. n. 225, de O Bolo, Ourense. Teónimos: Coronus: CIL II 5562, de Cerzedelo, Guimarães, Braga; y Corobelicobo (según Búa) en Arroyomolinos de la Vera, vid. supra. 
peor de los encargos posibles. Por fortuna, contamos con la guía de Knapp (1922: 339-384), quien trató de razonar la cronología de las inscripciones del centro de la Península; como en ese conjunto se incluyeron también las de la parte avileña del Valle del Tiétar, sus argumentos parecen, en principio, aplicables a La Vera.

De las cuatro piezas, la más sencilla de datar es la última, el epitafio degradado de Losar de la Vera. La invocación a los Manes comenzó a utilizarse en las lápidas sepulcrales de Tarraco a comienzos del siglo II d.C. (Alföldy 2011: CVI), primero expressis verbis $\mathrm{y}$, luego, en distintos grados de abreviación, siguiendo en uso hasta bien entrado el siglo III. Aunque entre las estudiadas por Knapp no hay tan claras pautas cronológicas, el investigador americano extiende este criterio a las inscripciones del centro peninsular, sobre todo si, como en el caso que nos ocupa, hay también letras en nexo, que es otra marca de fecha tardía. El deterioro del monumento de Losar de la Vera nos priva de otros posibles indicadores cronológicos, que pueden suplirse con la opinión de uno de nosotros que prospectó la zona del hallazgo: los restos cerámicos hallados en superficie apuntan a que el asentamiento alcanzó su apogeo entre los siglos III-IV.

Otra cuestión distinta es la data de los tres altares. De ellos, en dos — los de las fincas "Pascuala" y "El Salobral"- los teónimos van acompañados de los epítetos deus, dea, que es un fenómeno bien fechado en las provincias galas y germanas, donde estuvo en uso durante más o menos un siglo a partir de mediados del siglo II d.C. (Raepsaet-Charlier 1990: 13). Está por ver hasta qué punto ese criterio es aplicable a Lusitania en general y a la remota comarca que nos interesa, en particular. Por ejemplo, para el altar de Viseu al que antes hemos aludido, sus editores sugieren datarlo "de meados / $2^{\circ}$ metade do século I d.C.", basándose en la apariencia del texto (Fernandes et alii 2009: 150); en cambio, Hernando (2005: cat. nn. 146-151) cita la práctica galo-germana como criterio para fechar las dedicatorias del Deus Velicus del santuario de Postoloboso, que pertenecen al mismo milieu geográfico y cultural que nuestros altares; y, usando también argumentos paleográficos, tres de los exvotos de Quangeius (los únicos fechados por sus editores) se sitúan en diversos momentos del siglo II d.C. (vid. supra nota 15 para las referencias apropiadas).

No cabe duda que lo más llamativo de estas dos aras es precisamente la apariencia de sus respectivos letreros, que combinan una factura "descuidada" (seguramente el resultado del bosquejo a mano alzada el texto para guiar la composición y posterior corte de las letras) con algunos rasgos gráficos singulares que sirven como indicios cronológicos. Así la G del altar de "Pascuala" es, para Knapp (1992: 374), una forma que se hace común a partir del siglo II y durante el III, mientras que la misma letra con el espolón vertical del ara de "El Salobral" es menos significativa porque se encuentran ejemplos de esa grafía desde el siglo I al IV. Son indicios también de fecha tardía la A con medio filete, la $\mathrm{L}$ con el brazo descendente y la $\mathrm{T}$ con travesaño corto ${ }^{27}$; en cambio, las E y F cursivas, que aparecen en inscripciones muy antiguas, siguen usándose ocasionalmente en otros periodos, a veces por mor de arcaísmo, como probablemente sucede con la pieza de "El Salobral". Todo considerado, pues, resulta plausible que ambos altares puedan fecharse desde mediados del siglo II hasta bien entrado el siglo III, siendo quizá el de "Pascuala" más tardío que el de "El Salobral".

Finalmente, el altar de Band(-) se diferencia de los otros dos por el trazo regular de las letras, el corte de estas y su regular distribución en renglones, aunque no se respete la división de palabras. En contraste con las anteriores inscripciones, es patente que en esta, la talla del letrero fue precedida de un cierto diseño, realizado probablemente usando escuadra y compás. Aún así, el resultado es una capital cuadrada "aligerada" gracias a detalles como los bucles no cerrados de la $\mathrm{B}$ y de la $\mathrm{R}$, el desigual brazo intermedio de la $\mathrm{E}$, etc. La experiencia demuestra que los rasgos anteriores no siempre tienen valor cronológico, sino que dependen de otros factores como la habilidad del cantero, el precio del encargo o la calidad de la piedra. Sin embargo, nuestra impresión es que este altar debe de ser más temprano que los otros dos, posiblemente de fines del siglo I a comienzos del siguiente. Nótese que en la media docena de ofrendas de Band(-) para las que se ha propuesto una fecha, esta oscila entre comienzos del siglo I y fines del II d.C.

Cuatro epígrafes no dan demasiado de sí, pero hay al menos dos conclusiones que se imponen. La primera es que presentan la misma composición tipológica que señalábamos al principio como un rasgo destacado del conjunto epigráfico de la región: un alto porcentaje de dedicatorias sacras, un pequeño número de epitafios. Que esto sea una consecuencia del azar o una particularidad sobre la que fundamentar juicios históricos, es algo que el tiempo dirá, porque nuestro trabajo es solo una demostración de lo poco explorada que está la zona y lo fructíferos que pueden ser futuros esfuerzos.

${ }^{27}$ Para la A: $C I L$ II, $4127=\mathrm{II}^{2} / 14$ 993, de Tarraco, datada por Alföldy a partir del s. III y que, a diferencia de nuestro caso, el perfil está anclado en el fuste derecho. Las L como la descrita aparecen en Roma a partir de finales del siglo II (Gordon 1957: 106). Sobre la T, Knapp 1992: 376. 
La segunda conclusión es de mayor enjundia histórica. Como ya se ha dicho, desde hace más de 30 años se sabe que en el extremo oriental del valle del Tiétar, justo en la confluencia de este río con la garganta de Alardos, en el paraje llamado de Postoloboso, existió un santuario cuyo numen titular fue el deus Velicus. A pesar del número de aras encontradas en torno a la ermita allí existente y en sus alrededores, la sorpresa de la excavación del lugar fue que reportó un magro número de hallazgos banales y ninguna estructura edilicia (Fernández Gómez 1973: 231-235). Se ha discutido si ello es debido a que los edificios anteriores fueron arrasados al construirse la ermita, si ésta se encuentra algo desplazada del santuario antiguo o, por el contrario, éste nunca contó con una construcción digna porque la presencia divina emanaba del lugar mismo. La cuestión sigue sin resolverse tras la última campaña de excavaciones en Postoloboso (Schattner et alii 2006: 210), pero quienes han escrito sobre el sitio son unánimes notando su espectacular emplazamiento, a espaldas del impresionante farallón del pico Almanzor y con vistas sobre una amplia porción del valle del Tajo que llega hasta las estribaciones de los montes de Toledo. Quizá la santidad del santuario que presentamos en este trabajo, el fanum Quangei, derivaba justamente de lo contrario, de la impresión causada por el paraje cerrado e inhóspito de un bosque de ribera. Pero ambos parecen ser lugares de culto sin aparentes infraestructuras y obligan a reformularse cómo fueron los santuarios extra-urbanos de Hispania.

\section{BIBLIOGRAFÍA}

Abascal Palazón, J. M. 1994: Los nombres personales en las inscripciones latinas de Hispania, Murcia.

Alfenim, R. 1991 : "Ex-voto a Quangeio Turicaeco", Ficheiro Epigráfico 38, 174.

Alföldy, G. 1975: Die römischen Inschriften von Tarraco, Berlin.

Alföldy, G. 2011: "De typologia et chronologia monumentorum inscriptorum Tarraconensium", G. Alföldy (ed.), Inscriptiones Hispaniae Latinae. Vol II, ed. altera, fasc. 14 bis: Conventus Tarraconensis. Colonia Iulia Urbs Triumphalis Tarraco, Berlin, CV-CVII.

Alvarado Gonzalo, M. de, Blanco Fernández, J. L. y González Cordero, A. 1993: "Las joyas orientalizantes de Villanueva de la Vera (Cáceres)", Trabajos de Prehistoria 50 (1), 249- 262.

Bernardo Stempel, P. de 2003: "Los formularios teonímicos Bandus con su correspondiente femenino
Bandua y unas isoglosas célticas", Conimbriga 42, 197-212.

Blanco Freijeiro, A. 1959: "Pátera argêntea com representaçâo de uma divinidade lusitana", Revista de Guimarães 69 (3-4), 453-457.

Blázquez Martínez, J. M. 1979: "Ultimas aportaciones a las religiones primitivas de Hispania", Estudios dedicados a Carlos Callejo Serrano, Cáceres, 131170.

Bueno Ramírez, P., Rovira Llorens, S. y González Cordero, A. 2000: “Áreas de habitación y sepulturas de falsa cúpula en la cuenca extremeña del Tajo: acerca del poblado con necrópolis del canchal en Jaraíz de la Vera (Cáceres)", Extremadura Arqueologica 8, 475-514.

Callejo Serrano, C. 1963: "Fichas de Arqueología extremeña", Archivo Español de Arqueología 36 (107-108), 222-228.

Callejo Serrano, C. 1967: "Cédulas epigráficas del campo norbense", Zephyrus 18, 86-139.

Carbonell i Manils, J. y Gimeno Pascual, H. 2005: "Un fanum en Trujillo", Faventia 27(2), 7- 16.

Cerrillo Cuenca, E. y González Cordero, A. 2001: "El proceso de neolitización en la comarca extremeña de La Vera", Madrider Mitteilungen 42, 1-32.

Collingwood, R. G. y Wright, R. P. 1965: The Roman Inscriptions of Britain, vol. I, Inscriptions on Stone, Oxford.

Curado, F. P. 1984: "Ara a Duangeius, de Penamacor", Ficheiro Epigráfico 7, 26.

Curado, F. P. 1987a: "Fragmento de Ara de Nisa", Ficheiro Epigráfico 23, 103.

Curado, F. P. 1987b: "Aras a Quangeius da Ribeira da Nave (Sabugal)", Ficheiro Epigráfico 22, 100.

Curchin, L. A. 1985: "Epigraphic Notes from the Spanish Meseta", Zeitschrift für Papyrologie und Epigraphik 58, 244-246.

Delamarre, X. 2004: "Gallo-Brittonica: transports, richesse et générosité chez les anciens Celtes", Zeitschrift für Celtische Philologie 54, 121-131.

Dragojevi -Josifovska, B. 1982: Inscriptions de la Mésie supérieure, VI: Scupi et la région de Kumanovo, Beograd.

Dubourdieu, A. y Scheid, J. 2000: "Lieux de culte, lieux sacrés: les usages de la langue", A. Vauchez (ed.), Lieux sacrés, lieux de culte, sanctuaires. Approches terminologiques méthodologiques, historiques et monografiques, Roma, 59-80.

Encarnação, J. de 1984: Inscrições romanas do Conventus Pacensis. Subsídios para o estudo da romanização, Coimbra.

Encarnaçao, J. de 1987: "Divindades indígenas da Lusitânia", Conimbriga 26, 5-37. 
Encarnaçao, J. de 2002: "O sexo dos deuses romanos”, S. Crespo Ortíz de Zárate y Á. Alonso Ávila (eds.), Scripta antiqua in honorem Angel Montenegro Duque et José María Blázquez Martínez Valladolid, 517-525.

Espinosa, U. 1986: Epigrafía romana de La Rioja, Logroño.

Esteban Ortega, J. y Salas Martín, J. 2003: Epigrafía romana y cristiana del Museo de Cáceres, Cáceres.

Fauduet, I., Dominique, B., Rey-Vodoz, V. y Cabuy, Y. 1993: Atlas des sanctuaires romano- celtiques de Gaule: les fanums, Paris.

Fernandes, L. de S., Carvalho, P. S. y Figueira, N. 2009: "Divindades indígenas numa ara inédita de Viseu", Paleohispanica 9, 143-155.

Fernández Freire, C. 2009: Paisajes agrarios pre y protohistóricos en la comarca de la Vera Alta (Cáceres): un enfoque arqueo-geográfico, Tesis de Doctor en Historia de la Universidad Complutense, dirigida por J. M. Vicent García, Madrid (disponible en http://eprints.ucm.es/8442/).

Fernández Gómez, F. 1973: "El santuario de Postoloboso (Candeleda, Avila)", Noticiario Arqueológico Hispánico 2, 173-270.

Garcia, J. M. 1984: Epigrafia lusitano-romana do Museu Tavares Proença Júnior, Castelo Branco.

García, J. M. 1985: "Quangeio, deus lusitano”, História 76, 22-32.

García, J. M. 1991: Religiões Antigas de Portugal. Aditamentos e observações às 'Religiões da Lusitânia' de J. Leite de Vasconcelos. Fontes Epigráficas, Lisboa.

Gómez-Pantoja, J. L. 2011: "Un nuevo terminus Augustalis en Lusitania”, A. Sartori y A. Valvo (eds.), Identità e Autonomie nel mondo romano occidentale (Iberia-Italia Italia- Iberia. III Covegno Internazionale di Epigrafia e Storia Antica, Gargnano, 12-15 maggio 2010), 29, Faenza, 291-317.

Gómez-Pantoja, J. L., Madruga Flores, J. V. y González Cordero, A. 2011: “¿Un raro tipo de monumento sepulcral?”, J. Andreu Pintado, D. Espinosa y S. Pastor (eds.), Mors ómnibus instat, Madrid, 383-406.

González Cordero, A. y Hernández López, M. 1992: "El sepulcro turriforme de Jarandilla (Cáceres)", Alcántara 20, 49-60.

González Cordero, A. 2003: "El monumento funerario de Aldeanueva de la Vera", La Revista. La comarca de la Vera 2, 4-5.

González Cordero, A. 2005: "Mausoleos romanos en La Vera”, La Revista. La comarca de la Vera 9, 4-5.

González Cordero, A. 2007: "Los mosaicos de las villas romanas del Campo Arañuelo y La Vera",
XIV Coloquios histórico-culturales del Campo Arañuelo, Navalmoral de la Mata, 83-104.

González Rodríguez, M. Cruz 2008: "La epigrafía de los espacios sagrados”, J. M. Iglesias Gil e I. Rodá de Llanza (eds.), Actas de los XVIII Cursos Monográficos sobre el Patrimonio Histórico, Reinosa-Santander, 37-56.

González-Conde Puente, M. P. 1988: "Bassus Turobrigensis y la inscripción de Ataecina en Caleruela (Toledo)", Studia Historica 6, 131-132.

Gordon, J. S. y Gordon, A. E. 1957: Contributions to Palaeography of Latin inscriptions, Berkeley.

Hernando Sobrino, R. 2005: Epigrafía romana de Ávila, Bordeaux.

Hurtado de San Antonio, R. 1977: Corpus provincial de inscripciones latinas: Cáceres, Cáceres.

Knapp, R. C. 1992: Latin Inscriptions from Central Spain, Berkeley.

L rincz, B. 1994-2002: Onomasticon provinciarum Europae Latinarum, Budapest - Wien.

Morestin, H. 1976: "Inscriptions religieuses et pierres funéraires inédites ou peu connues de la provincia de Logroño", Archivo Español de Arqueología 49 (133-134), 181-194.

Navarro, M., y Ramírez Sádaba, J. L. 2003: Atlas antroponímico de la Lusitania romana. MéridaBurdeos.

Nègre, E. 1990: Toponymie générale de la France, I: Formations préceltiques, celtiques, romanes, Genève.

Olivares Pedreño, J. C. 1997: "El dios indígena Bandua y el rito del toro de San Marcos", Complutum 8, 205-222.

Olivares Pedreño, J. C. 1999: “Aportaciones al estudio de Arentius, Arentia y las divinidades indígenas masculinas de la religión de Egitania", Ilu. Revista de Ciencias de las Religiones 4, 139-172.

Pedrero, R. 1999: “Aproximación lingüística al teónimo lusitano-gallego Bandue/Bandi”, F. Villar y F. Beltrán Lloris (eds.), Pueblos, lenguas y escrituras en la Hispania prerromana (Actas del VII coloquio sobre lenguas y culturas prerromanas), Salamanca, 535-543.

Prósper, B. M. 2002: Lenguas y religiones prerromanas del occidente de la Península Ibérica, Salamanca.

Raepsaet-Charlier, M. T. 1990: Diis deabusque sacrum: Formulaire votif et datation dans les trois Gaules et les deux Germanies (Gallia romana), Paris.

Redentor, A. 2002: Epigrafia romana na região de Bragança, Lisboa.

Rodríguez Colmenero, A. 1997: Aquae Flaviae, I. Fontes Epigráficas da Gallaecia meridional interior, Chaves. 
Schallmayer, E. 1990: Der römische Weihebezirk von Osterburken I: Corpus der griechischen und lateinischen Beneficiarier-Inschriften des Römischen Reiches, Stuttgart.

Schattner, T. G., Mariné, M., Koch, M. y Geldmacher, N. 2006: "Bericht über die Kampangen der Jahre 2004/2005 im Heilgtum des Vaelicus in Postoloboso (Candeleda, Prov. Avila): mit einer Katalogbeitrag von M. A. Cebrián Sánchez", Madrider Mitteilungen 47, 193-220.

Smith, W. 1857: Dictionary of Greek and Roman Geography, Boston.

Soria Sánchez, V. 1979: "Hallazgos arqueológicos recientes en Extremadura”, A. Beltrán Martínez (ed.), Actas del XV Congreso Arqueológico Nacional (Lugo 1977), Zaragoza, 903-911.

Speidel, M. P. 1994: Die Denkmäler der Kaiserreiter. Equites singulares Augusti, Köln.

Stilwell, R., MacDonald, W. y McAlister, M., 1976: The Princeton Encyclopedia of Classical Sites, Princeton.

Szabó, Á. y Tóth, E. 2003: Bölcske: römische Inschriften und Funde, Budapest.

Tovar, A. (1966-1967): "L'inscription du cabeço das Fráguas et la langue des lusitaniens", Etudes Celtiques 11 (2), 254-268.

Troisgros, H. 1975: Borvo et Damona: divinités gallo-romaines des eaux thermales, Bourbonne-lesBains.

Vallejo Ruiz, J. M. 2005: Antroponimia indígena de la Lusitania romana, Vitoria-Gasteiz.

Velaza, J. 1995: "Dis Inferis Manibus: Nuevos testimonios en inscripciones romanas de Hispania", Sylloge Epigraphica Barcinonensia 28, 201207.

Vives, J. 1969: Inscripciones cristianas de la España romana y visigoda, Barcelona.

Vollgraff, G. 1931-1932: "Inscriptiones traiectenses", Mnemosyne 59, 249-265.

Woodard, R. D. 2006: Indo-European sacred space: Vedic and Roman cult, Urbana.

Recibido: 10-06-2012

Aceptado: 26-09-2012 